Article

\title{
Sectoral Differences in the Choice of the Time Horizon during Estimation of the Unconditional Stock Beta
}

\author{
Dimitrios Dadakas ${ }^{1}$, Christos Karpetis ${ }^{2}$, Athanasios Fassas ${ }^{3}$ and Erotokritos Varelas ${ }^{4, *}$ \\ 1 Department of Economics, University of Ioannina, Panepistimioupoli, 45510 Ioannina, Greece \\ 2 Department of Balcan, Slavic and Oriental Studies, University of Macedonia, 156, Egnatia Street, \\ P.O. Box 1591, 54006 Thessaloniki, Greece; ckarpet@uom.edu.gr \\ 3 The University of Sheffield International Faculty, City College, 3 Leontos Sofou Street, 54626 Thessaloniki, \\ Greece; A.Fassas@sheffield.ac.uk \\ 4 Department of Economics, University of Macedonia, 156, Egnatia street, P.O. Box 1591, 54006 Thessaloniki, \\ Greece; varelas@uom.edu.gr \\ * Correspondence: ddadakas@cc.uoi.gr; Tel.: +30-6932-228-917 \\ Academic Editor: Nicholas Apergis \\ Received: 8 July 2016; Accepted: 2 December 2016; Published: 17 December 2016
}

\begin{abstract}
The stock beta coefficient literature extensively discusses the proper methods for the estimation of beta as well as its use in asset valuation. However, there are fewer references with respect to the appropriate time horizon that investors should utilize when evaluating the risk-return relationship of a stock. We examine the appropriate time horizon for beta estimation, differentiating our results by sector according to the Industry Classification Benchmark. We employ data from the NYSE and estimate varying lengths of beta employing data from 30 to 250 trading days. The constructed beta series is then examined for the presence of breaks using the endogenous structural break literature. Results show evidence against the use of betas that employ more than 90 trading days of data provisional to the sector under study.
\end{abstract}

Keywords: stock beta; endogenous structural breaks; time horizon

JEL Classification: C10; C22; C59; G12; G19

\section{Introduction}

Stock beta is used by investors to examine the risk-return relationship, evaluate the return of an asset and compare the relative performance of assets. It is also employed in Capital Budgeting to identify profitable ventures through the Net Present Value (NPV) method, which requires the estimation of the Weighted Average Cost of Capital (WACC) and the cost of equity often calculated through the Capital Asset Pricing Model (CAPM).

Despite the fact that the literature has presented substantial methodological advances in the estimation of beta ${ }^{1}$, investors often rely on secondary information and simple unconditional 30 to 180-day betas published through the media and through financial services. While those estimates

1 Numerous articles have dealt with issues of heteroscedasticity, autocorrelation and the time variation of betas through the estimation of ARCH and GARCH models, GARCH conditional betas, stochastic volatility conditional betas, Kalman Filter approaches, Flexible Least Squares, Markov switching approaches [1-5]; see Hollstein and Prokopczuk [6] for a recent and comprehensive comparison of market beta estimation techniques. Another set of literature has concentrated on the estimation of realized betas to improve beta forecasts $[7,8]$. We refer to them in a separate footnote in the literature section of this paper. 
of beta reported usually originate from seven different sources [9], they also differ substantially $[5]^{2}$. Those differences can, amongst other reasons, be partially attributed to the choice of market index, the calendar period employed and the returns "time horizon".

This article concentrates on determining the appropriate time horizon for the estimation of stock beta. The time horizon, or period length, refers to how far back we should look at the data to estimate the beta or, simply stated, the number of observations that should be included in the estimation of beta. As the number of observations included in the estimation increases, there is a higher probability that significant changes in beta occur. Wrongfully choosing the proper time frame may result in a misrepresentation of the systematic risk, which, in turn, may lead to wrong investment decisions and market inefficiencies.

To discuss the proper time horizon we construct "time-series" of varying beta-lengths and examine them for the presence of structural breaks using the methodologies presented by the endogenous structural break literature. If, i.e., a structural break on the beta series is observed within 40 trading days and investors employ a longer time horizon beta, then systematic risk will be misrepresented. We employ all 2641 stocks in the NYSE to avoid problems generated by company-specific breaks. Results are broken down by sector using the Industry Classification Benchmark (ICB-ICB1-2-3). While this practice is computationally intensive, it allows an averaging of company-specific events that might not be related to a general sector reaction to market conditions. We employ daily returns data and compare the estimated average sectoral break dates with the most commonly used $30 / 60 / 90 / 120 / 180$-day betas. Our analysis allows us to infer whether there is a maximum time horizon per sector that investors should employ for their decisions.

\section{Literature Review}

Beta is reported for investors through a number of financial providers, and, in its most simple form, it is estimated through OLS regression analysis of market returns on the individual stock returns providing unconditional estimates of beta while assuming that they are constant over time. Betas cannot be estimated ex ante as it not possible to document investors' expectations; therefore, beta is calculated using historic data of the individual company's shares and the market index [10].

The estimation of beta with historical data presents itself with a number of problems. One of those problems refers to the choice of interval length i.e., the choice between using daily, weekly, monthly or annual returns for the construction of stock and index returns which may affect the size of the beta. Past research has shown that the simple average of betas tends to increase as the returns interval is lengthened [11]. Further breakdown suggests that estimates for securities with small (large) market values tend to increase (decrease) as the return measurement interval is lengthened [12,13]. The choice of interval length also has an impact on the standard errors of the estimates. Betas based on daily returns provide smaller standard errors than betas based on longer interval returns [14]; however, high frequency data is also more likely to create error heteroscedasticity problems resulting in inefficiency of the estimates [15].

To deal with contradictory evidence, Levy et al. [16] (also see Gunthorpe and Levy [17]), who associate the interval length with the holding period, assert that the interval length employed for the estimation of beta should match the investor's holding period ${ }^{3}$. Recent literature that has dealt with the choice of the interval in the estimation of beta through the use of realized beta and volatility measures [7,8,23-27] provides support for the use of high frequency data. This strain of literature compares forecasted to realized measures of beta estimated through a multivariate continuous time

2 Some sites such as Bloomberg allows users to specify the period of estimation while other sites such as Compustat and Dow Jones do not.

3 Other studies that have concentrated on the impact of the choice of interval length on the estimation of beta and the resulting effect on the estimates of beta include Altman et al. [18], Baesel [19], Roenfeldt et al. [20], Smith [21], Alexander and Chervany [22]. 
stochastic volatility diffusion ${ }^{4}$. The realized betas provide a starting point for the evaluation of the accuracy of forecasts of beta measures. Cenesizogloy et al. [29], who compared forecasted values of beta to realized values, amongst other results, found that higher frequency returns result in more accurate one-month-ahead beta forecasts rather than returns measured at a lower frequency.

A second problem encountered in the estimation of beta with historical data is related to the choice of the time horizon. As the number of observations that are employed in the estimation of beta increases-i.e., as the estimation period increases-the estimate of beta improves in terms of precision. However, increases in the period length compromise the validity of the results as firm-specific structural breaks might be present as a direct cause of recapitalization, acquired divisions, spin-off divisions or changes in product mix leading to changes in the beta [14].

Theobald [30] was one of the first to tackle this issue and concluded that increasing the length of the estimation period results in the reduction of sampling fluctuations. However, a higher estimation period also implies an increased probability of betas having changed so that optimal data length involves a trade-off between these two opposing forces. Daves et al. [14] incorporated in his study the effect on beta of differing both interval length and the estimation period. Their conclusions with respect to interval length were concrete; however, their results do not provide adequate evidence for the proper estimation period. They examined eight different periods for estimation that vary from one to eight years and found that, although longer periods result in a tighter error for the estimate of beta, they also result in a higher probability that there is a significant change in the beta. Longer estimation periods are more likely to bias the estimates. Their results favor the use of up to a three-year beta. Within this time frame, beta estimates capture a large percentage of the maximum possible reduction in the standard error.

Recent literature also adapted the realized beta and volatility measures to infer the accuracy of forecasted beta measures for different time horizons. Reeves and $\mathrm{Wu}$ [31] used high frequency data and compared forecasted and realized betas using a set of time horizons between three and 60 months for the United States, United Kingdom and the Australian markets. Their results suggested that daily returns data for a period of 12 months produced the most accurate one-quarter-ahead forecasts of beta ${ }^{5}$. Results were consistent across all three markets that were examined in their analysis. Similar results are provided by Cenesizoglu et al. [29] who found that when the highest reliable return frequency measurement is daily, a constant beta model with 12 months of information results in the most accurate one-month-ahead beta forecasts.

Contributing to the literature on the time horizon of beta, we follow a different approach and adapt the endogenous structural break literature to study the proper time horizon. More specifically, we examine a constructed beta "time-series" for the presence of structural breaks separating our results by industry using ICB classifications ${ }^{6}$. We employ daily data as it uses more detailed information about the variability of the stock price and the index [11], it provides smaller standard errors for the estimates [14] and also seems to provide more accurate forecasts [31]. More important, however, is the fact that the daily returns data is one of the main tools employed by investors and provided by financial services which is relevant to the motivation of this study. Finally, we add to recent research

4 The reason for the appearance of these models was that while betas were recognized to be time-varying in nature (time invariance of beta is a basic assumption of the CAPM), there were no models or forecasting techniques that could outperform the constant beta model [28]. This advancement was a response to the availability of higher frequency financial data that allowed for the development of new estimators and evaluation criteria. Barndorff-Nielsen and Shephard [8] and Andersen et al. [26] provided the foundation for the computation of realized betas by assuming that security prices follow a multivariate continuous time stochastic volatility diffusion. While the estimation of realized betas does not fit the scope of this paper, we reflect on them in the conclusions as they present the next step of this research.

5 Moreover, they found that the 12-month beta estimates from the constant beta model resulted in reduction of mean squared error forecasts in excess of $30 \%$ as compared to autoregressive models commonly reported in the literature.

6 Past research has concentrated on the differences in beta amongst sectors. Rosenberg [32] noted that companies active in the Agriculture and Utilities industry show lower levels of betas while companies in the Electronics, Air Transport and Securities show higher. Liu [33] found that Real Estate shows high values of time varying betas. 
attempts that have identified industry-related patterns that standard asset pricing models cannot explain effectively [34]. Existing evidence indicates that industries affect capital structure, but popular asset pricing models such as the one-factor capital asset pricing model or the multifactor models of Chen et al. [35] and Fama and French [36] simply confer no role to industries.

\section{Data and Methodology}

Daily data for 2641 stocks from the NYSE was downloaded using the Metastock software for the period of 1 September 2011 to 31 August 2012. A second data set spanning from 1 September 2006 to 31 August 2007 was employed to compare and contrast the results. The first period in our sample (2006-2007) exhibits an upward trending low level of volatility while the second period (2011-2012) exhibits a downward trending high level of volatility ${ }^{7}$. Differences in the level of volatility were statistically significant, which allows us to infer how volatility might shorten/lengthen the periods that we observe a structural break on the average beta series. For the market index we used the S\&P 500. The data downloaded was adjusted for stock splits and dividends.

Beta can be estimated through either the market model or the excess return model [37]. We estimate beta by using simple returns such that

$$
R_{s, t, i}=a_{s, t}+\beta_{s, t} R_{t, i}^{m}+e_{s, t, i}
$$

where $R^{s}$ represents the daily return on stock $s, s=1, \ldots, 2641$ for all the stocks in the NYSE, $R^{m}$ represents the daily return on the market, $t$ represents the length of the beta included in the regression where $t$ ranges from a minimum of 30 daily observations to 223 daily observations and $i$ represents the $i^{\text {th }}$ observation $\forall i=1, \ldots, 252^{8}$. Returns on stocks and the market are estimated in continuous time using logarithmic differences of daily returns.

For every one of the stocks in our data, we obtain a vector of 223 observations that represents betas of different lengths, from 30-day beta to 252-day beta. The beta "time-series" is constructed through a rolling regression process. We first estimate a 30 day-beta by using Equation (1) on the 30 most recent observations in our sample for security $s=1$. We then repeat this process with the 31 most recent observations to obtain the 31-day beta. We roll the regression backwards until we reach the 252-day beta. This process provides us with a total of 223 estimates of beta for stock $s=1$. We thus construct a "time-series" for each one of the securities ( $s=1$ through 2641$)$ by estimating $223 \times 2641$ regressions as described by Equation (1) that allows us to examine how beta evolves as more information is included in the estimation ${ }^{9}$. The process is repeated for the second sample in our data.

On these 2641 constructed series of betas, we employ the methodology presented by Zivot and Andrews (ZA henceforth) [38] to examine for structural breaks and the stationarity of the series. Methods preceding chronologically the ZA methodology, which might be used to determine the presence of a unit root in a time series, are the ones proposed by Dickey and Fuller [39,40], Kwiatkowski et al. [41] and Phillips and Perron [42], who drew a unit root test using non-parametric statistical methods. However, various Dickey-Fuller and Phillips-Perron test statistics are biased toward the acceptance of the unit root null in the presence of structural breaks, i.e., structural breaks reduce the power of the unit root test. Therefore, Perron [43-46], Zivot and Andrews [38], Banerjee et al. [47], and Perron and Vogelsang [48-50] have developed tests, in the context of which the significance of

7 Using the realized volatility index $R V_{t}=\sqrt{252 \times \sum_{i=0}^{21}\left(\ln \left(\frac{S P X_{t-i}}{S P X_{t-i-1}}\right)\right)^{2}} /{ }_{21} \times 100$, our first sample showed an index of 10.84 and our second sample 18.56. These were statistically different at $a=1 \%$.

8252 daily observations were downloaded minus the 30 most recent observations allow for the estimation of 30-day betas all the way to 252 day betas.

9 Average $t$-day betas were estimated for the whole sample of 2641 stocks in the NYSE and were found to be very close to 1. 
the unit root null is tested, allowing for a break in a time series and choosing the break date either exogenously or endogenously.

Zivot and Andrews [38] and Perron [46] were the first to propose determining a break point "endogenously" from the data. There are two main arguments for the use of the ZA method that we employ. Given that we use daily data in our paper, there is always the possibility that we might observe changes in the level of prices that are not due to a structural break but rather to news that, in most cases, does not affect the data generating process. The ZA model captures structural changes that do not present themselves at a specific point in time (one day) but rather in multiple times, which implies that any structural changes that the model results capture are changes that have a rather permanent effect on the data generating process.

The endogenous structural break literature evolved further when a new set of methods allowed the concurrent estimation of more than one endogenous structural breaks on the same time series [51-53]. However, given that in a period of 30 to 250 trading days, like the one that we examine, we do not expect to have more than one important structural break, we employ the ZA model that allows the estimation of the one most important structural break that takes place during the period of study. In other words, even if we were to employ one of the methodologies that would allow us to estimate more than one (innovational outlier) break, the second break could in all likelihood be identified as a shock that does not affect the data generating process and is not a real structural break. Using the ZA methodology, the investigations for a unit root in the time series $\left\{Y_{t}\right\}_{t=1}^{T}$ involves the (OLS) estimation of the following three models:

$$
\begin{gathered}
A \text { (break in level) }: Y_{t}=\mu+\beta t+\theta D U_{t}+a Y_{t-1}+\sum_{i=1}^{k} c_{i} \Delta Y_{t-i}+u_{t}, \\
B \text { (break in trend) }: Y_{t}=\mu+\beta t+d D T_{t}+a Y_{t-1}+\sum_{i=1}^{k} c_{i} \Delta Y_{t-i}+u_{t}, \\
C \text { (break in level \& trend) }: Y_{t}=\mu+\beta t+\theta D U_{t}+d D T_{t}+a Y_{t-1}+\sum_{i=1}^{k} c_{i} \Delta Y_{t-i}+u_{t}
\end{gathered}
$$

where $\Delta$ is the difference operator, $t$ is a simple time trend, $D U$ is a level dummy variable where $D U_{t}=0(1)$ if $t \leq T_{B}\left(t>T_{B}\right), D T$ is a slope dummy where $D T_{t}=0\left(t-T_{B}\right)$ if $t \leq T_{B}\left(t>T_{B}\right)$, $1<T_{B}<T$ with $T$ : the number of used observations and $T_{B}$ : the point in time where the structural break occurs.

The determination of the lag parameter $k$ ensures that the residuals are not correlated. Its value is endogenously determined following the general to specific recursive procedure [43,44]. We examine the significance of the lag coefficient $c_{i}$ for a maximum $k$ of 14 . The parameter $k$ could be estimated using Schwert's [54] rule that suggests that $k_{\max }=\operatorname{int}\left[12\left(\frac{T+1}{100}\right)^{1 / 4}\right]$ for $T>100$, which, in our case, implies that $k_{\max }=14$.

The $t$-statistic $T_{\hat{c}_{k} \max }=\frac{\hat{c}_{k} \max }{\text { s.e. }\left(\hat{c}_{k} \max \right)}$ is examined as compared to the value 1.64 in absolute terms. If $\left|T_{\hat{c}_{k} \max }\right|<1.64$, then $k \neq k^{\max }$ and the procedure was repeated by decreasing the length of the lag by 1 such that $k=k^{\max }-1$. We continued this procedure until $\left|T_{\hat{c}_{k} \max }\right| \geq 1.64$ or until all lags are eliminated at $k=0$.

After the selection of the lag length parameter $k$, say $k^{*}$, the Equations (2)-(4) are estimated using the OLS method for all potential break dates TB, assuming that $2<T_{B}<T-1$. The date for which the estimated value of the $t$-statistic $T_{\hat{a}}=(\hat{a}-1) /$ s.e. $(\hat{a})$ is minimized, and for which the probability of rejecting the unit root null is maximized, is considered to be the endogenously determined break date of the examined series. In the context of the performed unit root test, the statistical significance of the unit root null without a break in series is tested against the alternative of a break-stationary process. 
In this article, we employ only the third model for our estimations. Sen [55] argues that if we employ model A when in reality the break occurs by a model such as C, in other words if the break is related to the slope dummy, then we lose the power of the test. If, on the other hand, we employ model $\mathrm{C}$ yet the true break occurs according to model $\mathrm{A}$, then we have only minor losses in power. Additional limitations to our estimation are due to the fact that we include a trend in the specification of model C. When there is no trend in the data, the power of the test for the null hypothesis is reduced as the addition of a trend variable increases hypothesis testing critical values, whereas when the series does include a trend and a trend component is not added in the specification, we might lose explanatory power of the model [56].

The resulting combinations of break dates are examined for differences amongst groups in the NYSE as defined by first, second and third level ICB categories. A full description of the categories can be found on the NYSE Website.

\section{Results}

We examine the differences in the average break dates starting with level 1 ICB groups presented in Table $1^{10}$. Columns 3-6 present the results for the first set of data that spans from 2011 to 2012, while the remaining columns (7-10) examine the period 2006-2007. The first set of results that is presented in each one of the two samples is the number of NYSE stocks that fall in the respective category. The average break date for each category produced is presented next, together with the respective standard deviation. i.e., for the 143 companies that are listed in the "Basic Materials" category for the 2011-2012 data, the average break date occurs after 101 daily observations with a standard deviation of 54.2 days. To assist in the interpretation, and since the standard deviation is a relatively large number, the next column $($ Perc $<60)$ presents the percentage of NYSE stocks within each category where we observe a break with a beta employing up to 60 trading days of information. For the first category, $14 \%$ of the stocks exhibited a beta series with structural breaks within 60 trading days. Respectively, for the 2006-2007 data, there are 117 stocks that fall in the first category of Basic Materials, the average break date occurs after 113 days of information are included in the estimations, and the standard deviation is lower and equal to 44.5 . Moreover, $19.7 \%$ of the stocks in this category exhibit a beta series with a structural break within 60 trading days.

Using first level ICB categories, most of the stock's beta series presented a break date once 90 trading days of information were included in the estimations. This presents strong evidence in favor of the use of betas that employ less than 60 days of information, some evidence against the use of betas that employ between 60 and 90 days of information (due to the high standard deviation) and strong evidence against the use of betas with more than 120 days of information as significant changes in the average beta-series seem to appear. Despite the average break date implied by the analysis, the reader should be cautious in the interpretation due to the high standard deviation observed in all categories ${ }^{11}$; Column 5 (Perc $<60)$ helps us analyze this in more detail. For Basic Materials, the average break date appears after 101 days of information; however, $14 \%$ of the stocks in the category exhibit a break date of less than 60 trading days. The maximum percentage appears in the Oil and Gas category with $28.6 \%$ of the stocks showing a break date of less than 60 trading days. For these stocks, even the use of the 60-day beta could result in miscalculation of the systematic risk, the expected returns, and the investment decisions ${ }^{12}$.

10 Only 2324 out of 2641 stocks in the NYSE were included in the analysis as some lacked an ICB classification match and some exhibited negative betas when few observations were included in the regression.

11 The large standard deviation suggests that there are numerous stocks in each category both on the upper and the lower side of the average. This, however, represents the main reason that we took all of the stocks in NYSE so as to allow company specific events to average out, which allows us to glimpse at the sectoral averages.

12 We would therefore need to look at ICB2-3-4 categories for more detailed information. Moreover, about $40 \%$ of the stocks in each category are non-stationary at the $1 \%$ level, $50 \%$ at the $5 \%$ level and $60 \%$ at the $10 \%$ level of significance. 
Table 1. Average break dates by 1st level ICB Categories.

\begin{tabular}{cccccccccc}
\hline \multirow{2}{*}{$\begin{array}{c}\text { Category } \\
\text { Number }\end{array}$} & ICB1 Category & \multicolumn{4}{c}{$\mathbf{2 0 1 1 - 2 0 1 2}$} & \multicolumn{4}{c}{$\mathbf{2 0 0 6 - 2 0 0 7}$} \\
\cline { 3 - 9 } & & $\begin{array}{c}\text { No. of } \\
\text { Stocks }\end{array}$ & $\begin{array}{c}\text { Av. } \\
\text { Break }\end{array}$ & $\begin{array}{c}\text { Av. } \\
\text { Std }\end{array}$ & Perc. < 60 & $\begin{array}{c}\text { No. of } \\
\text { Stocks }\end{array}$ & $\begin{array}{c}\text { Av. } \\
\text { Break }\end{array}$ & $\begin{array}{c}\text { Av. } \\
\text { Std }\end{array}$ & Perc. < 60 \\
\hline 1 & Basic Materials 2,6,10 & 143 & 101 & 54.2 & $14.0 \%$ & 117 & 113 & 44.5 & $19.7 \%$ \\
2 & Consumer Goods 3,5,7,9,10 & 203 & 115 & 61.8 & $19.2 \%$ & 151 & 115 & 41.3 & $15.9 \%$ \\
3 & Consumer Services 2,6,10 & 224 & 102 & 54.0 & $21.4 \%$ & 184 & 113 & 40.9 & $13.0 \%$ \\
4 & Financials 6,10 & 887 & 106 & 55.8 & $20.6 \%$ & 829 & 112 & 39.9 & $14.8 \%$ \\
5 & Health Care 2,6,10 & 105 & 100 & 51.1 & $27.6 \%$ & 95 & 107 & 40.5 & $15.8 \%$ \\
6 & Industrials 1,3,4,5,7,9,10 & 356 & 113 & 57.4 & $18.8 \%$ & 322 & 107 & 44.6 & $22.7 \%$ \\
7 & Oil \& Gas 2,4,6,10 & 168 & 97 & 54.4 & $28.6 \%$ & 143 & 100 & 43.6 & $14.7 \%$ \\
8 & Technology 10 & 88 & 110 & 60.2 & $26.1 \%$ & 76 & 109 & 42.2 & $19.7 \%$ \\
9 & Telecommunications 6,10 & 50 & 96 & 49.4 & $24.0 \%$ & 46 & 111 & 43.6 & $21.7 \%$ \\
10 & Utilities 1 through 9 & 100 & 131 & 61.5 & $20.0 \%$ & 90 & 104 & 40.0 & $8.9 \%$ \\
\hline
\end{tabular}

Source: Own Estimations. Superscripts on the categories reflect statistically significant differences with row categories presented in column 1. ICB: Industry Classification Benchmark.

Additionally, when we examine the average break date among the groups, we find that there are significant differences at the $a=0.05$ level between categories. These are highlighted with the superscript on column 2 and are estimated only for the 2012 data. For example, Basic Materials differ significantly with categories on rows 2, 6 and 10 that are the Consumer Goods category, Industrials and Utilities. These differences present an interesting contrast with the results by Rosenberg [32] and Liu [33] who found differences in beta levels amongst different categories of companies.

Comparing the results from the 2006-2007 sample with those from the 2011-2012 sample, we observe that during the period prior to the Global Financial Crisis (GFC), the beta-series was more stable as both the average break date was higher for most of the categories and the standard deviation was also lower. The main exception occurs in the Utilities category that seems to present a much higher average break date as compared to the pre-GFC period. These observations can also be tied to the different market volatilities in the two samples. We recall that the 2006-2007 sample presented a period with an upward trending low level of volatility, whereas the 2011-2012 sample presented a period with downward trending high level of volatility. Consequently, the lower average break dates in the 2011-2012 sample may be the result of increased volatility observed during and post-GFC.

Second and third ICB level categories are shortly presented with the help of Tables 2 and $3^{13}$. With ICB2, we see that there is more differentiation that becomes apparent in terms of the average break date. Utilities, and Personal and Household Goods exhibit the most significant differences with the rest of the sectors showing more stable beta series with break dates at a longer time horizon, reflecting different sector responses to economy wide fluctuations and beta stability. On the other hand, Telecommunications, Oil and Gas, Media, Food and Beverages and Basic Resources have significantly lower levels of break dates. Within-category significant differences are only observed between categories $2 b$ and $2 c$. Average break dates for the pre-GFC period are observed at a longer time horizon with the exception of Industrials and Utilities, consistent with our ICB1 conclusions on the effect of increased post-GFC market volatility.

Similar to the conclusions from ICB1, analysis results suggest that there are substantial group differences that would direct us towards the use of different length beta for ICB2 sub-categories to account for the significant changes in the beta. On average, there is strong evidence for the use of up to 60-day betas, some evidence against the use of betas that employ between 60 and 90 trading

13 Fourth level ICB categories are available upon request only, as the great number of categories and the limited number of observations in many of these categories prevents us from either effectively discussing the results within the limits of an article or reaching useful conclusions. 
days of information and strong evidence against the use of any beta that employs more than 90 days of information.

Table 3 presents ICB3 results where we now see ample differentiation in the average break dates between categories. Using ICBS3, there is again strong evidence for the use of up to 60-day beta for most of the categories, similar to the results implied when we employed the ICB1 and ICB2.

Post-GFC stability in the beta series is now apparent in the Forestry and Paper category, Leisure Goods, Personal Goods, Non-Equity Investment Instruments, Life Insurance, Construction and Materials, General Industrials, Industrial Transportation, Oil Equipment Services and Distribution, Software and Computer Services, Electricity and Gas, Water and Industrials.

One final step in our analysis consisted of examining whether there are differences in the beta series break dates that can be attributed to market capitalization. Six levels of market capitalization were examined (first column-Table 4) for within-sample and between-sample differences. Results are consistent with previous analysis showing a decrease in the average break date of the beta series for the post-GFC 2011-2012 data. Between-sample differences were statistically significant for companies with capitalization between $\$ 50$ million and $\$ 2$ billion (categories 2 and 3) as indicated by the last column in Table 4, where we present the significance value for the $t$-test for the differences. For companies in these categories, post-GFC stability of the beta series decreased showing significantly higher vulnerability to market conditions and higher levels of volatility. Category 2 and 3 companies with relatively low levels of capitalization were thus most vulnerable to the changing market conditions. An interesting observation is that companies with low levels of market capitalization (category 1) did not show any between-sample statistical differences on the break dates of the beta series. These results suggest that these companies were not significantly affected by changing market conditions and the increased volatility. This could be attributed to less exposure to international markets that smaller companies may have. While the most evident difference was observed on category 6 companies with capitalization of more than $\$ 200$ billion where the average break date decreased from 110 to 84 days of trading data, the low number of companies in this category did not allow any inference, as differences were not statistically significant. However, for the companies in the sample, we could argue that exposure to the global markets and the inability to hedge during the global turmoil might have contributed to significantly higher vulnerability shown with a decrease in the average break date.

The within-sample analysis showed only a few significant differences in the 2006-2007 sample. More specifically, the 3rd category (300 million-2 billion) was significantly different from the 4 th and 5th categories ( 2 billion-10 billion and 10 billion-200 billion). No significant within-sample differences were found in the 2011-2012 data ${ }^{14}$.

14 The analysis was repeated employing both market capitalization and ICB1 level analysis. Those results are available upon request. 
Table 2. Average break dates by 2nd level ICB categories.

\begin{tabular}{|c|c|c|c|c|c|c|c|c|c|c|}
\hline \multirow{2}{*}{ Category Number } & \multirow{2}{*}{ ICB1 } & \multirow{2}{*}{ ICB2 } & \multicolumn{4}{|c|}{$2011-2012$} & \multicolumn{4}{|c|}{ 2006-2007 } \\
\hline & & & No. of Stocks & Av. Break & Av. Std & Perc. $<60$ & No. of Stocks & Av. Break & Av. Std & Perc. $<60$ \\
\hline $1 \mathrm{a}$ & \multirow{2}{*}{ Basic Materials } & Basic Resources & 79 & 96 & 47.5 & $20 \%$ & 65 & 113 & 43.3 & $23 \%$ \\
\hline $1 \mathrm{~b}$ & & Chemicals & 64 & 109 & 61.1 & $6 \%$ & 52 & 112 & 46.2 & $15 \%$ \\
\hline $2 \mathrm{a}$ & \multirow{3}{*}{ Consumer Goods } & Automobiles \& Parts & 34 & 112 & 62.0 & $9 \%$ & 23 & 114 & 39.6 & $13 \%$ \\
\hline $2 b$ & & Food \& Beverage & 51 & 99 & 54.5 & $22 \%$ & 39 & 116 & 40.4 & $15 \%$ \\
\hline $2 c$ & & Personal \& Household Goods & 118 & 122 & 63.9 & $21 \%$ & 89 & 114 & 42.5 & $17 \%$ \\
\hline $3 a$ & \multirow{3}{*}{ Consumer Services } & Media & 64 & 97 & 49.6 & $28 \%$ & 41 & 115 & 39.6 & $7 \%$ \\
\hline $3 b$ & & Retail & 96 & 103 & 55.0 & $18 \%$ & 82 & 115 & 39.9 & $10 \%$ \\
\hline $3 c$ & & Travel \& Leisure & 64 & 104 & 57.3 & $20 \%$ & 61 & 107 & 43.3 & $21 \%$ \\
\hline $4 a$ & \multirow{3}{*}{ Financials } & Banks & 124 & 110 & 55.9 & $19 \%$ & 103 & 121 & 39.4 & $14 \%$ \\
\hline $4 \mathrm{~b}$ & & Financial Services & 672 & 104 & 54.9 & $20 \%$ & 647 & 109 & 39.8 & $15 \%$ \\
\hline $4 \mathrm{c}$ & & Insurance & 91 & 115 & 60.9 & $24 \%$ & 79 & 118 & 39.4 & $13 \%$ \\
\hline 5 & Health Care & Health Care & 105 & 100 & 51.1 & $28 \%$ & 95 & 107 & 40.5 & $16 \%$ \\
\hline $6 a$ & \multirow{2}{*}{ Industrials } & Construction \& Materials & 52 & 108 & 58.4 & $15 \%$ & 51 & 100 & 41.5 & $29 \%$ \\
\hline $6 \mathrm{~b}$ & & Industrial Goods \& Services & 304 & 114 & 57.3 & $19 \%$ & 271 & 109 & 45.0 & $21 \%$ \\
\hline 7 & Oil and Gas & Oil \& Gas & 168 & 97 & 54.4 & $29 \%$ & 143 & 100 & 43.6 & $15 \%$ \\
\hline 8 & Technology & Technology & 88 & 110 & 60.2 & $26 \%$ & 76 & 109 & 42.2 & $20 \%$ \\
\hline 9 & Telecommunications & Telecommunications & 50 & 96 & 49.4 & $24 \%$ & 46 & 111 & 43.6 & $22 \%$ \\
\hline 10 & Utilities & Utilities & 100 & 131 & 61.5 & $20 \%$ & 90 & 104 & 40.0 & $9 \%$ \\
\hline
\end{tabular}

Source: Own Estimations. 
Table 3. Average break dates by 3rd level ICB categories.

\begin{tabular}{|c|c|c|c|c|c|c|c|c|c|c|}
\hline \multirow{2}{*}{ Category Number } & \multirow{2}{*}{ ICB2 } & \multirow{2}{*}{ ICB3 } & \multicolumn{4}{|c|}{ 2011-2012 } & \multicolumn{4}{|c|}{ 2006-2007 } \\
\hline & & & No. of Stocks & Av. Break & Av. Std & Perc. $<60$ & No. of Stocks & Av. Break & Av. Std & Perc. $<60$ \\
\hline 1a & \multirow{3}{*}{ Basic Resources } & Forestry \& Paper & 14 & 109 & 57.1 & $21 \%$ & 11 & 81 & 42.2 & $64 \%$ \\
\hline $1 \mathrm{~b}$ & & Industrial Metals & 36 & 100 & 54.3 & $28 \%$ & 28 & 113 & 40.0 & $18 \%$ \\
\hline $1 \mathrm{c}$ & & Mining & 29 & 84 & 28.9 & $10 \%$ & 26 & 127 & 41.3 & $12 \%$ \\
\hline 2 & Chemicals & Chemicals & 64 & 109 & 61.1 & $6 \%$ & 52 & 112 & 46.2 & $15 \%$ \\
\hline 3 & Automobiles \& Parts & Automobiles \& Parts & 34 & 112 & 62.0 & $9 \%$ & 23 & 114 & 39.6 & $13 \%$ \\
\hline $4 a$ & \multirow{2}{*}{ Food and Beverages } & Beverages & 7 & 120 & 69.3 & $14 \%$ & 7 & 140 & 7.2 & $0 \%$ \\
\hline $4 \mathrm{~b}$ & & Food Producers & 44 & 96 & 52.0 & $23 \%$ & 32 & 110 & 42.8 & $19 \%$ \\
\hline $5 a$ & \multirow{4}{*}{$\begin{array}{l}\text { Personal and } \\
\text { Household Goods }\end{array}$} & Household Goods & 57 & 110 & 58.6 & $23 \%$ & 44 & 116 & 42.7 & $18 \%$ \\
\hline $5 b$ & & Leisure Goods & 22 & 136 & 67.8 & $27 \%$ & 15 & 116 & 40.0 & $7 \%$ \\
\hline $5 c$ & & Personal Goods & 31 & 141 & 66.1 & $10 \%$ & 24 & 111 & 45.4 & $17 \%$ \\
\hline $5 \mathrm{~d}$ & & Tobacco & 8 & 103 & 66.2 & $38 \%$ & 6 & 112 & 45.5 & $33 \%$ \\
\hline 6 & Media & Media & 64 & 97 & 49.6 & $28 \%$ & 41 & 115 & 39.6 & $7 \%$ \\
\hline $7 \mathrm{a}$ & \multirow[b]{2}{*}{ Retail } & Food \& Drug Retailers & 10 & 112 & 55.4 & $10 \%$ & 8 & 130 & 17.7 & $0 \%$ \\
\hline $7 \mathrm{~b}$ & & General Retailers & 86 & 102 & 55.1 & $19 \%$ & 74 & 114 & 41.3 & $11 \%$ \\
\hline 8 & Travel \& Leisure & Travel \& Leisure & 64 & 104 & 57.3 & $20 \%$ & 61 & 107 & 43.3 & $21 \%$ \\
\hline 9 & Banks & Banks & 124 & 110 & 55.9 & $19 \%$ & 103 & 121 & 39.4 & $14 \%$ \\
\hline $10 \mathrm{a}$ & \multirow{4}{*}{ Financial Services } & Equity Investment Instruments & 379 & 103 & 51.5 & $21 \%$ & 405 & 112 & 39.5 & $13 \%$ \\
\hline $10 \mathrm{~b}$ & & General Financial & 126 & 109 & 58.1 & $23 \%$ & 116 & 108 & 41.7 & $18 \%$ \\
\hline $10 \mathrm{c}$ & & Nonequity Investment Instrumen & 6 & 142 & 67.2 & $17 \%$ & 3 & 122 & 31.7 & $0 \%$ \\
\hline $10 \mathrm{~d}$ & & Real Estate & 161 & 102 & 59.5 & $16 \%$ & 123 & 103 & 38.9 & $22 \%$ \\
\hline $11 \mathrm{a}$ & \multirow[b]{2}{*}{ Insurance } & Life Insurance & 35 & 109 & 59.0 & $20 \%$ & 28 & 106 & 38.3 & $18 \%$ \\
\hline $11 \mathrm{~b}$ & & Nonlife Insurance & 56 & 119 & 62.2 & $27 \%$ & 51 & 124 & 38.7 & $10 \%$ \\
\hline $12 \mathrm{a}$ & \multirow{2}{*}{ Health Care } & Health Care Equipment \& Servic & 78 & 99 & 48.7 & $26 \%$ & 68 & 107 & 38.1 & $15 \%$ \\
\hline $12 \mathrm{~b}$ & & Pharmaceuticals \& Biotechnolog & 27 & 103 & 58.6 & $33 \%$ & 27 & 105 & 46.8 & $19 \%$ \\
\hline 13 & Construction and Materials & Construction \& Materials & 52 & 108 & 58.4 & $15 \%$ & 51 & 100 & 41.5 & $29 \%$ \\
\hline $14 \mathrm{a}$ & \multirow{6}{*}{$\begin{array}{l}\text { Industrial Goods } \\
\text { and Services }\end{array}$} & Aerospace \& Defense & 26 & 111 & 51.7 & $12 \%$ & 28 & 116 & 42.1 & $14 \%$ \\
\hline $14 \mathrm{~b}$ & & Electronic \& Electrical Equipm & 51 & 114 & 63.8 & $25 \%$ & 44 & 110 & 48.0 & $20 \%$ \\
\hline $14 \mathrm{c}$ & & General Industrials & 36 & 115 & 55.6 & $25 \%$ & 35 & 106 & 39.9 & $23 \%$ \\
\hline $14 \mathrm{~d}$ & & Industrial Engineering & 59 & 119 & 60.0 & $15 \%$ & 59 & 110 & 43.2 & $19 \%$ \\
\hline $14 \mathrm{e}$ & & Industrial Transportation & 55 & 120 & 57.3 & $20 \%$ & 41 & 95 & 42.0 & $29 \%$ \\
\hline $14 \mathrm{f}$ & & Support Services & 77 & 107 & 54.0 & $18 \%$ & 64 & 114 & 49.8 & $22 \%$ \\
\hline $15 \mathrm{a}$ & \multirow{3}{*}{ Oil and Gas } & Alternative Energy & 1 & 64 & & $0 \%$ & 1 & 128 & & $0 \%$ \\
\hline $15 \mathrm{~b}$ & & Oil \& Gas Producers & 116 & 91 & 52.2 & $33 \%$ & 96 & 101 & 45.3 & $16 \%$ \\
\hline $15 \mathrm{c}$ & & Oil Equipment, Services \& Dist & 51 & 111 & 57.5 & $20 \%$ & 46 & 98 & 40.4 & $13 \%$ \\
\hline $16 \mathrm{a}$ & \multirow{2}{*}{ Technology } & Software \& Computer Services & 42 & 113 & 60.6 & $19 \%$ & 35 & 99 & 37.1 & $20 \%$ \\
\hline $16 \mathrm{~b}$ & & Technology Hardware \& Equipmen & 46 & 107 & 60.3 & $33 \%$ & 41 & 117 & 44.9 & $20 \%$ \\
\hline $17 a$ & \multirow{2}{*}{ Telecommunications } & Fixed Line Telecommunications & 28 & 110 & 57.0 & $21 \%$ & 25 & 111 & 40.6 & $20 \%$ \\
\hline $17 \mathrm{~b}$ & & Mobile Telecommunications & 22 & 79 & 30.7 & $27 \%$ & 21 & 111 & 47.9 & $24 \%$ \\
\hline $18 \mathrm{a}$ & \multirow{2}{*}{ Utilities } & Electricity & 66 & 132 & 60.0 & $15 \%$ & 54 & 99 & 41.0 & $11 \%$ \\
\hline $18 \mathrm{~b}$ & & Gas, Water \& Multiutilities & 34 & 128 & 65.1 & $29 \%$ & 36 & 110 & 38.1 & $6 \%$ \\
\hline
\end{tabular}


Table 4. Average break dates by market capitalization.

\begin{tabular}{ccccccccc}
\hline \multirow{2}{*}{ Category Number } & \multirow{2}{*}{ Market Capitalization } & \multicolumn{3}{c}{ 2011-2012 } & \multicolumn{3}{c}{ 2006-2007 } & \multirow{2}{*}{ Sig } \\
\cline { 3 - 7 } & & Obs. & Av. Break & Av. Std & Obs. & Av. Break & Av. Std & \\
\hline 1 & Up to \$50 million & 766 & 109 & 55.7 & 619 & 110 & 42.7 & 0.668 \\
2 & \$5 million-\$300 million & 262 & 104 & 53.6 & 214 & 111 & 40.7 & 0.081 \\
3 & \$300 million-\$2 billion & 527 & 107 & 55.8 & 438 & 114 & 41.9 & 0.033 \\
4 & \$2 billion-\$10 billion & 487 & 110 & 60.3 & 436 & 107 & 40.7 & 0.445 \\
5 & \$10 billion-\$200 billion & 379 & 105 & 57.8 & 360 & 108 & 42.4 & 0.389 \\
6 & Above \$200 billion & 10 & 84 & 43.7 & 10 & 110 & 49.2 & 0.218 \\
\hline
\end{tabular}

Source: Own Estimations. Sig column examines the row differences between the average break date in the 2011-2012 data and the 2006-2007 data.

\section{Conclusions}

We constructed time series of the beta values for each one of the stocks in the NYSE for the period of 1 September 2011 to 31 August 2012 and for the period 1 September 2006 to 31 August 2007. The constructed series were examined for endogenous structural breaks using model $C$ from the Zivot and Andrews [38] method. The objective of the paper was to examine the break dates inferred by our analysis for each ICB category and discuss the maximum time horizon for the estimation of the beta that investors should use.

Results were examined by looking at the average break in each ICB category at all levels of categorization. Our results for both data sets in our analysis support that the 120- and 180-day beta commonly used will, in most cases, miscommunicate the level of systematic risk to investors as this time horizon is adequate for substantial changes to affect most of the companies' beta. The use of up to 90-day betas seems to be appropriate for the estimation of the systematic risk of a stock allowing, however, for some differentiation of this conclusion with respect to certain categories where both a high standard deviation is observed as well as a large percentage of stocks that present a break in the beta series within 60 trading days.

Our results are in line with some of the conclusions by Theobald [30] and Daves et al. [14] who suggest that, while incorporating longer estimation period reduces sample fluctuation and produces tighter errors, it also increases the probability of betas having changed. Our results suggest that those changes are likely to occur for most stocks within 90 trading days. On the other hand, our estimates, which present a reliability horizon of 90 days on average, conflict with Reeves and $\mathrm{Wu}$ [31] who found that 12-month daily returns produce the most accurate one-quarter-ahead forecasts.

This difference from the conclusions reached from studies utilizing realized vs. forecasted measures such as Reeves and $\mathrm{Wu}$ [31] motivate our future research, as they dictate the need to fully study how structural breaks affect the forecasting accuracy of beta. The next step in this research is therefore to benchmark and evaluate forecasted values of beta from different time horizons that incorporate structural breaks, as estimated by our analysis, against realized betas using the methods presented by Andersen et al. [7], Andersen et al. [23], Andersen et al. [25,26] and Barndorff-Nielsen and Shephard [8].

Author Contributions: All authors contributed equally to the paper.

Conflicts of Interest: The authors declare no conflict of interest.

\section{References}

1. Mergner, S.; Bulla, J. Time-varying Beta Risk of Pan-European Industry Portfolios: A Comparison of Alternative Modeling Techniques. Eur. J. Financ. 2008, 14, 771-802. [CrossRef]

2. Bollerslev, T. Modelling the Coherence in Short-Run Nominal Exchange Rates: A Multivariate Generalized ARCH Model. Rev. Econ. Stat. 1990, 72, 498-505. [CrossRef]

3. Giannopoulos, K. Estimating the Time Varying Components of International Stock Market Risk. Eur. J. Financ. 1995, 1, 129-164. [CrossRef] 
4. Brooks, R.D.; Faff, R.W.; McKenzie, M.D. Time varying Beta Risk of Australian Industry Portfolios: A Comparison of Modelling Techniques. Aust. J. Manag. 1998, 23, 1-22. [CrossRef]

5. Balyeat, R.B.; Cagle, J.A.B.; Phan, L. Alternatives for Published Calculated Beta Estimates. J. Int. Financ. Econ. 2012, 12, 57-63.

6. Hollstein, F.; Prokopczuk, M. Estimating beta. J. Financ. Quant. Anal. 2016, 51, 1437-1466. [CrossRef]

7. Andersen, T.G.; Bollerslev, T.; Diebold, F.X.; Wu, J. Realized beta: Persistence and predictability. Adv. Econ. 2006, 20, 1-39.

8. Barndorff-Nielsen, O.N.; Shephard, N. Econometric Analysis of Realized Volatility and its Use in Estimating Stochastic Volatility Models. J. R. Stat. Soc. 2002, 64, 253-280. [CrossRef]

9. Lamb, R.P.; Northington, K. The Root of Reported Betas. J. Invest. 2001, 10, 50-53. [CrossRef]

10. Damodaran, A. Risk and Return in Practice Estimation of Discount Returns. In Corporate Finance; Damodaran, A., Ed.; Wiley: New York, NY, USA, 1997.

11. Brzeszzynski, J.; Gajdka, J.; Schabek, T. The Role of Stock Size and Trading Intensity in the Magnitude of the "Interval Effect" in Beta Estimation: Empirical Evidence from the Polish Capital Market. Emerg. Mark. Financ. Trade 2011, 47, 28-49. [CrossRef]

12. Pogue, G.A.; Solnik, B. The Market Model Applied to European Common Stock: Some Empirical Results. J. Financ. Quant. Anal. 1974, 9, 917-944. [CrossRef]

13. Reilly, F.K.; Wright, D.J. A Comparison of Published Betas. J. Portfolio Manag. 1988, 14, 64-69. [CrossRef]

14. Daves, P.R.; Ehrhardt, M.C.; Kunkel, R.A. Estimating Systematic Risk: The Choice of Return Interval and Estimation Period. J. Financ. Strateg. Decis. 2000, 13, 7-13.

15. Jacobsen, B.; Dannenburg, D. Volatility Clustering in Monthly Stock Returns. J. Empir. Financ. 2003, 10, 479-503. [CrossRef]

16. Levy, H.; Gunthorpe, D.; Wachowitz, J. Beta and an Investor's Holding Period. Rev. Bus. 1994, 15, 32-35.

17. Gunthorpe, D.; Levy, H. Portfolio Composition and the Investment Horizon. Financ. Analysts J. 1994, 50, 51-56. [CrossRef]

18. Altman, E.I.; Jacquillet, B.; Levasseur, M. Comparative Analysis of Risk Measures: France and the United States. J. Financ. 1974, 29, 1495-1511. [CrossRef]

19. Baesel, J.B. On the Assessment of Risk: Some Further Considerations. J. Financ. 1974, 29, 1491-1494. [CrossRef]

20. Roenfeldt, R.L.; Grienpentrof, G.L.; Pflaun, C.C. Further Evidence on the Stationarity of Beta Coefficients. J. Financ. Quant. Anal. 1978, 13, 117-221. [CrossRef]

21. Smith, V.K. The Effect of Intervaling on Estimating Parameters of the Capital Asset Pricing Model. J. Financ. Quant. Anal. 1980, 13, 313-332. [CrossRef]

22. Alexander, G.J.; Chervany, N.L. On the Estimation and Stability of Beta. J. Financ. Quant. Anal. 1980, 15, 123-137. [CrossRef]

23. Andersen, T.G.; Bollerslev, T. Answering the Skeptiks. Yes. Standard Volatility Models Do Provide Accurate Forecasts. Int. Econ. Rev. 1998, 39, 885-905. [CrossRef]

24. Foster, D.P.; Nelson, D.B. Continuous record asymptotics for rolling sample variance estimators. Econometrica 1996, 64, 139-174. [CrossRef]

25. Andersen, T.G.; Bollerslev, T.; Diebold, F.X.; Ebens, H. The distribution of realized stock return volatility. J. Financ. Econ. 2001, 61, 43-76. [CrossRef]

26. Andersen, T.G.; Bollerslev, T.; Diebold, F.X.; Labys, P. Modeling and forecasting realized volatility. Econometrica 2003, 71, 579-625. [CrossRef]

27. Andersen, T.G.; Bollerslev, T.; Diebold, F.X.; Wu, J.G. A Framework for Exploring the Macroeconomic Determinants of Systematic Risk. Am. Econ. Rev. 2005, 95, 398-404. [CrossRef]

28. Hopper, V.J.; Ng, K.; Reeves, J.J. Quarterly Beta Forecasting: An Evaluation. Int. J. Forecast. 2008, 24, 480-489. [CrossRef]

29. Cenesizoglu, T.; Liu, Q.; Reeves, J.J.; Wu, H.N. Monthly Beta Forecasting with Low-, Medium- and High-Frequency Stock Returns. J. Forecast. 2016, 35, 528-541. [CrossRef]

30. Theobald, M. Beta Stationarity and Estimation Period: Some Analytical Results. J. Financ. Quant. Anal. 1981, 16, 747-757. [CrossRef]

31. Reeves, K.K.; Wu, H.N. Constant Versus Time-Varying Beta Models: Further Forecast Evaluation. J. Forecast. 2013, 32, 256-266. [CrossRef] 
32. Rosenberg, B. Prediction of Common Stock Betas. J. Portf. Manag. 1985, 11, 5-14. [CrossRef]

33. Liu, Y.T. An Empirical Study on Beta Coefficient and its Related Characteristic in Shanghai Stock Market. Manag. Sci. Chin. 2004, 17, 29-35.

34. Chou, P.-H.; Po-Hsin, H.; Kuan-Cheng, K. Do industries matter in explaining stock returns and asset-pricing anomalies? J. Bank. Financ. 2012, 36, 355-370. [CrossRef]

35. Chen, N.F.; Roll, R.; Ross, S.A. Economic forces and the stock market. J. Bus. 1986, 59, 383-403. [CrossRef]

36. Fama, E.F.; French, K.R. Common risk factors in the returns on stocks and bonds. J. Financ. Econ. 1993, 33, 3-56. [CrossRef]

37. Bodie, Z.; Jane, A.; Marcus, A. Invest; McGraw-Hill: New York, NY, USA, 2002.

38. Zivot, E.; Andrews, D.W.K. Further Evidence on the Great Crash the Oil-Price Shock, and the Unit Root Hypothesis. J. Bus. Econ. Stat. 1992, 10, 251-270. [CrossRef]

39. Dickey, D.A.; Fuller, W.A. Distribution of Estimators for Autoregressive Time Series with a Unit Root. J. Am. Stat. Assoc. 1979, 74, 427-431. [CrossRef]

40. Dickey, D.A.; Fuller, W.A. Likelihood Ratio Statistics for Autoregressive Time Series with a Unit Root. Econometrica 1981, 49, 1057-1072. [CrossRef]

41. Kwiatkowski, D.; Phillips, P.C.B.; Schmidt, O.; Shin, Y. Testing the Null Hypothesis of Stationarity against the Alternative of a Unit Root. J. Econom. 1992, 54, 159-178. [CrossRef]

42. Phillips, P.C.B.; Perron, P. Testing for a Unit Root in Time Series Regressions. Biometrika 1988, 75, 335-346. [CrossRef]

43. Perron, P. The Great Crash, the Oil Price Shock and the Unit Root Hypothesis. Econometrica 1989, 57, 1361-1401. [CrossRef]

44. Perron, P. Further Evidence on Breaking Trend Functions in Macroeconomic Variables. J. Econom. 1989, 80, 355-385. [CrossRef]

45. Perron, P. Trend, Unit Root and Structural Change in Macroeconomic Time Series. In Cointegration for the Applied Economist; Rao, B.B., Ed.; Mac Millan Press: New York, NY, USA, 1994.

46. Perron, P. Testing for a Unit Root in a Time Series with a Changing Mean. J. Bus. Econ. Stud. 1997, 8, 153-162.

47. Banerjee, A.; Lumsdaine, R.L.; Stock, J.H. Recursive and Sequential Tests of the Unit-Root and Trend Break Hypothesis: Theory and International Evidence. J. Bus. Econ. Stat. 1992, 10, 271-287.

48. Perron, P.; Vogelsang, T.J. Testing for a Unit Root in a Time Series with a Changing Mean: Corrections and Extensions. J. Bus. Econ. Stud. 1992, 10, 467-470. [CrossRef]

49. Perron, P.; Vogelsang, T.J. Nonstationarity and Level Shifts with an Application to Purchasing power Parity. J. Bus. Econ. Stud. 1992, 10, 301-320. [CrossRef]

50. Perron, P.; Vogelsang, T.J. Additional Tests for a Unit Root Allowing for a Break in the Trend Function at an Unknown Time. Int. Econ. Rev. 1998, 39, 1073-1100.

51. Lumsdaine, R.L.; Papell, D.H. Multiple Trend Breaks and the Unit-Root Hypothesis. Rev. Econ. Stat. 1997, 79, 212-218. [CrossRef]

52. Lee, J.; Strazicich, M.C. Minimum Lagrange multiplier unit root test with two structural breaks. Rev. Econ. Stat. 2003, 85, 1082-1089. [CrossRef]

53. Kapetanios, G. Unit-root testing against the alternative hypothesis of up to $m$ structural breaks. J. Time Ser. Anal. 2005, 26, 123-133. [CrossRef]

54. Schwert, G.W. Tests for unit roots: A Monte Carlo investigation. J. Bus. Econ. Stat. 1989, 2, 147-159. [CrossRef]

55. Sen, A. On Unit Root Tests when the Alternative is a Trend Break Stationary Process. J. Bus. Econ. Stat. 2003, 21, 174-184. [CrossRef]

56. Ben-David, D.; Papell, D. Slowdowns and Meltdowns: Post War Growth Evidence from Emerging Markets. Rev. Econ. Stat. 1997, 28, 561-571.

(C) 2016 by the authors; licensee MDPI, Basel, Switzerland. This article is an open access article distributed under the terms and conditions of the Creative Commons Attribution (CC-BY) license (http://creativecommons.org/licenses/by/4.0/). 